\title{
Pre-treatment de-ritis ratio as a marker for cervical cancer: a study at regional cancer centre
}

\author{
Kumar S. ${ }^{1 *}$, Ramesh G. ${ }^{2}$, Roy M. ${ }^{3}$, Nelson N. ${ }^{4}$, Govardhan. ${ }^{5}$, Khaleel. ${ }^{6}$, Pallavi R. ${ }^{7}$ \\ DOI: https://doi.org/10.17511/ijmrr.2019.i03.03 \\ 1* Sandeep Kumar, Assistant Professor, Department of Gynaecological Oncology, Kidwai Memorial Institute of Oncology, Bengaluru, \\ Karnataka, India. \\ 2 Ramesh G., Professor, Department of Biochemistry, Kidwai Memorial Institute of Oncology, Bengaluru, Karnataka, India. \\ 3 Manisha Roy, Research Fellow, Department of Radiation Oncology, Kidwai Memorial Institute of Oncology, Bengaluru, Karnataka, India. \\ ${ }^{4}$ Nupur Nelson, Research Fellow, Department of Radiation Oncology, Kidwai Memorial Institute of Oncology, Bengaluru, Karnataka, India. \\ 5 Govardhan, Assistant Professor, Department of Radiation Oncology, Kidwai Memorial Institute of Oncology, Bengaluru, Karnataka, India. \\ ${ }^{6}$ Khaleel, Assistant Professor, Department of Radiation Oncology, Kidwai Memorial Institute of Oncology, Bengaluru, Karnataka, India. \\ 7 Pallavi R., Professor, Department of Gynaecological Oncology, Kidwai Memorial Institute of Oncology, Bengaluru, Karnataka, India.
}

Background: The role of AST/ALT ratio in prognostication of cancer cervix is not established in different study settings except for very few where they have highlighted on circulation of higher levels of AST and ALT in the cervical cancer patients. Moreover, there is a biological plausibility explained in one of the studies hence the study was conducted to elicit if the AST/ALT ratio could predict the prognosis of advanced cancer cervix before the initiation of treatment. Methodology: A follow up study was conducted among 122 newly diagnosed locally advanced carcinoma cervix patients in a regional cancer centre Bangalore from June 2015 to May 2018. All the basic data, normal and abnormal levels of serum Aspartate transaminase (AST), Alanine transaminase (ALT) and AST/ALT ratio were collected, followed up for one year and compared for overall survival using Log-rank test along with Kaplan-Meir curves. Receiver Operator Characteristic curves (ROC curves) were plotted to determine the poor outcome (death). Results: The mean age of the study participants was $50.4 \pm 10.6$ years. Mean follow up period was $4 \pm 3$ months (1-12 months). Median serum AST, ALT and de-ritis ratio did not differ among the different stages of cervical cancer. Area under the curve (AUCs) for de-ritis ratio was found to be not significant with very poor accuracy $(A \cup C=0.47 ; P>0.05)$. It was observed that there was no statistically significant difference between the groups in their survival rates. Conclusion: AST/ALT ratio cannot predict the prognosis of advanced cancer cervix before the initiation of treatment.

Keywords: Cervical cancer, De-ritis ratio, Prognostic marker

Corresponding Author

Sandeep Kumar, Assistant Professor, Department of Gynaecological Oncology, Kidwai Memorial Institute of Oncology, Bengaluru, Karnataka, India. Email: drsandeepkumar19@gmail.com
How to Cite this Article

Kumar S, Ramesh G, Roy M, Nelson N, Govardhan, Khaleel, Pallavi R. Pre-treatment de-ritis ratio as a marker for cervical cancer: a study at regional cancer centre. Int J Med Res Rev. 2019;7(3):162169. Available From

https://ijmrr.medresearch.in/index.php/ijmrr/article/ view/1054
To Browse

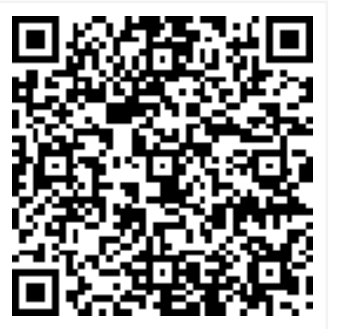

Manuscript Received 2019-05-04

Conflict of Interest No

Review Round 1
2019-05-14
Funding
Nil

Review Round 2
2019-05-20
$\begin{gathered}\text { Ethical Approval } \\ \text { Yes }\end{gathered}$

Review Round 3

Plagiarism X-checker $8 \%$
Accepted 2019-05-23

Note

() 2019 by Sandeep Kumar, Ramesh G., Manisha Roy, Nupur Nelson, Govardhan, Khaleel, Pallavi R. and Published by Siddharth Health Research and Social Welfare Society. This is an Open Access article licensed under a Creative Commons Attribution 4.0 International License https://creativecommons.org/licenses/by/4.0/ unported [CC BY 4.0]. 


\section{Introduction}

The commonest malignant tumours among female reproductive organs are of cervix and endometrium. Cervical carcinoma is most frequent in Latin America and Asian countries and the incidence of endometrial carcinoma is more common in western world. In different parts of India and adjacent countries, cervical carcinoma is reported as the commonest malignant neoplasm [1].

It is a multifactorial disease process and several risk factors include, early age intercourse, multiple sex partners, low socioeconomic status, and Human papillomavirus (HPV) infection. Chronic inflammation and infection over a long period of time have been recognized as major risk factor for disease initiation [2].

Malignancy is a systemic disease generally disrupting the subtle physiological homeostasis probably through the induction of systemic inflammatory process and respective organ systems may sense cancer through modest alterations of the most sensitive functional markers.

It seems to influence the neuro-humoral system with elevated cardiac biomarkers in the absence of a manifest cardiac disease, in terms of a subclinical involvement similarly for the liver and its markers too [3].

Liver biomarkers such as alanine aminotransferase (ALT), aspartate aminotransferase (AST) are a part of commonly requested 'Liver Function Test' (LFT) and the release of ALT and AST to the blood stream from liver cells rather represent hepatocellular damage or death than assessing functions of the liver $[3,4]$. An decreased de-ritis ratio has been associated withnon-alcoholic fatty liver disease (NAFLD) particularly with morbid obesity and NAFLD is associated with an increase in cardiovascular disease, diabetes and all-cause mortality [5]. The advances in molecular biology and clinical enzymology has implicated that malignancy could be explained on the basis of biochemical changes $[5,6]$.

Few studies have highlighted on circulating higher levels of AST and ALT in the cervical cancer patients and their use in the diagnosis and treatment monitoring of patients with cervical carcinoma [7].

Similarly, the relevance ofde-ritis ratio in implication of all-cause mortality, a growing body of evidence indicating that liver biomarkers may comprise
Prognostic information for various clinical conditions without primary pathological manifestations of the liver and biological plausibility as explained by Veeramalla Vhas made us to conduct this study to elicit if the AST/ALT ratio could predict the prognosis of locally advanced cancer cervix before the initiation of treatment $[3,4,8]$.

\section{Materials and Methods}

This is a retrospective analytical study conducted in the department of Biochemistry, Kidwai Memorial Institute of Oncology, Bangalore, Karnataka from June 2015 to May 2018.

\section{Patient Selection: Inclusion and Exclusion Criteria}

122 newly diagnosed patients with locally advanced carcinoma cervix (FIGO Stages IB2 through IVA) without any interventions were included in the studyand patients with incomplete records on pretreatment laboratory data were excluded. Patients with noted history of serious medical conditions, morbidly obese patient, liver abnormalities, patients with any metastasis to liver and alcoholics were excluded from the study.

Sample collection: $5 \mathrm{ml}$ of venous blood sample were collected under aseptic conditions in a plain tube. Sample was centrifuged at $3000 \mathrm{rpm}$ for $10 \mathrm{~min}$ and serum was separated within two hours of collection of blood. Care was taken to prevent hemolysis of the samples. Lipaemic and icteric samples were discarded. Serum Aspartate transaminase (AST), Alanine transaminase (ALT) and their ratio (AST/ALT) was estimated for all the patients. Serum AST and ALT were measured using Modified IFCC method.

All the patient's follow up information for the occurrence of primary and secondary endpoints were collected and compared among the early and late advanced stages of cervical cancer.

Operational definitions: Primary end point was disease-free survival, i.e. till the development of loco-regional recurrence (recurrences in vagina, uterus, cervix, parametrium) and distant metastases (the recurrences secondary to the primary tumor bed other than loco-regional recurrence was considered as distant metastases expect metastasis to liver). Secondary end point was overall survival.

Early advanced stage of cervical cancer: < III B

Late advanced stage of cervical cancer: $\geq$ IIIB 
Data Collection: The basic data viz., name of the patient, age, stage of cancer was taken and also data on blood investigations like serum Aspartate transaminase (AST), Alanine transaminase (ALT) and their ratio (AST/ALT) were collected from the records and were compared between the early and late advanced stages of cervical cancer.

The predictive ability of serum AST/ALT ratio and ALP in predicting the poor outcome (death) were assessed. The patients were further followed up for a period of 1 year and the survival rates of those with normal and abnormal values of de-ritis ratio were assessed.

Statistics: Data were entered into excel sheet and analysed using SPSS version 18.0. Results were presented as proportions and mean \pm SD. Mann Whitney $U$ test was used to compare the serum AST, ALT and de-ritis ratio with early and late advanced stages of cancer cervix. Receive Operator Characteristic curves (ROC curves) were plotted for AST/ALT ratio and ALP values in determining the poor outcome i.e., occurrence of death in advanced stages of Cervical Cancer. Time to event (death) analyses was done.

Data for patients who were alive were censored at date of last follow-up. The Kaplan-Meier curves were plotted. Overall survivals in both the groups were compared using log rank test with event being death. A $P$ value $<0.05$ was considered statistically significant.

\section{Results}

The mean age of the study participants was nearly 50.4 years with a standard deviation of 10.64 years. Majority of the patients were in the age group of $41-50$ years (31.1\%) followed by $51-60$ years (27.1\%). Highest proportion of patients were in III B stage (57.4\%) followed by stage IIB (34.4\%). $61.5 \%$ of the study subjects were in grade 2 followed by $33.6 \%$ were in grade 3 (Table1)

Table-1: Distribution of the study participants based on age, staging and grading of carcinoma cervix.

\begin{tabular}{|l|l|}
\hline \multicolumn{1}{|c|}{ Particulars } & \multicolumn{1}{c|}{$\mathbf{n ( \% )}$} \\
\hline Age in years (Mean \pm SD) & $50.4 \pm 10.64$ \\
\hline$\leq 40$ yrs & $26(21.3)$ \\
\hline $41-50$ yrs & $38(31.1)$ \\
\hline $51-60$ yrs & $33(27.1)$ \\
\hline $61-70$ yrs & $25(20.5)$ \\
\hline Stage & \\
\hline
\end{tabular}

\begin{tabular}{|l|l|}
\hline II A & $02(1.6)$ \\
\hline II B & $42(34.4)$ \\
\hline III A & $04(3.3)$ \\
\hline III B & $70(57.4)$ \\
\hline IV A & $03(2.5)$ \\
\hline IV B & $01(0.8)$ \\
\hline Grades & $05(4.1)$ \\
\hline Grade 1 & $75(61.5)$ \\
\hline Grade 2 & $41(33.6)$ \\
\hline Grade 3 & $01(0.8)$ \\
\hline Grade 4 &
\end{tabular}

The mean random blood glucose level was $130.4 \pm 63.87 \mathrm{mg} / \mathrm{dl}$ with a range of $67-510 \mathrm{mg} / \mathrm{dl}$. Mean total bilirubin, total proteins were $0.43 \pm 0.22$ $\mathrm{mg} / \mathrm{dl}$ and $7.79 \pm 0.57 \mathrm{~g} / \mathrm{dl}$ respectively.

Table-2: Means of blood parameters among the study participants

\begin{tabular}{|l|l|}
\hline \multicolumn{1}{|c|}{ Blood Parameters } & \multicolumn{1}{c|}{ Mean \pm SD } \\
\hline Random Blood Glucose Levels (mg/dl) & $130.4 \pm 63.87(67-510)$ \\
\hline Total Bilirubin $(\mathrm{mg} / \mathrm{dl})$ & $0.43 \pm 0.22(0.1-1.2)$ \\
\hline Total Proteins $(\mathrm{g} / \mathrm{dl})$ & $7.79 \pm 0.57(6.5-10.1)$ \\
\hline Serum Albumin(g/dl) & $3.92 \pm 0.45(2.3-5.1)$ \\
\hline Serum Alkaline Phosphatase (U/L) & $101.05 \pm 38.48(1.1-245)$ \\
\hline Serum ALT (U/L) & $21.21 \pm 10.39(7-90)$ \\
\hline Serum AST (U/L) & $12.48 \pm 10.86(2-79)$ \\
\hline Mean AST/ALT ratio Median - 1.9 & $2.3 \pm 1.9(0.3-18.0)$ \\
\hline Outcome $\bullet$ & \\
\hline Surviving & $108(88.5)$ \\
\hline Died & $14(11.5)$ \\
\hline Prognosis $\bullet$ & \\
\hline Stable & $65(53.3)$ \\
\hline Poor (Dropped/Recurrence/Metastasis) & $56(46.7)$ \\
\hline Progression of the disease $\boldsymbol{e}(\mathrm{n}=20-16.4 \%)$ & \\
\hline Metastasis & $14(70.0)$ \\
\hline Recurrence & $06(30.0)$ \\
\hline Mean follow-up period in months & $4 \pm 3(1-12)$ \\
\hline
\end{tabular}

\section{e- frequency (\%)}

Mean serum albumin, serum Alkaline Phosphatase, serum ALT, serum ALT and AST/ALT ratio were $3.92 \pm 0.45 \mathrm{~g} / \mathrm{dl}, 101.05 \pm 38.48 \mathrm{U} / \mathrm{L}, 21.21 \pm 10.39$ $\mathrm{U} / \mathrm{L}, 12.48 \pm 10.86 \mathrm{U} / \mathrm{L}$ and $2.3 \pm 1.9$ respectively. In majority $(88.5 \%)$ of the study participants the outcome was that they had survived during the study period whereas $11.5 \%$ of them had died. Looking in to the prognosis, $53.3 \%$ were stable whereas $46.7 \%$ had poor prognosis. Almost $70.0 \%$ of them had progression of disease with metastasis, $30.0 \%$ had recurrence. Mean follow up period was $4 \pm 3$ months with a range of 1-12 months. (Table2) 
On comparing the median serum AST, ALT and deritis ratio among different stages of cervical cancer, it was found that median serum AST levels was slightly higher among advanced stage ( $\geq$ III $B$ Stage) whereas median serum ALT levels and serum AST/ALT ratio did not differ among the different stages of cervical cancer. The difference among all the three variables with different stages was not found to be statistically significant $(P>0.05)$. (Table3)

Table-3: Comparison of serum AST, ALT and de-ritis ratio among different groups of stages

\begin{tabular}{|l|l|l|l|l|}
\hline \multicolumn{1}{|c|}{ Particulars } & \multicolumn{1}{|c|}{$\begin{array}{c}\text { < III B } \\
\text { Stage }\end{array}$} & \multicolumn{1}{|c|}{$\begin{array}{c}\text { III B } \\
\text { Stage }\end{array}$} & \multicolumn{1}{|c|}{ U-value (95\% } & $\begin{array}{c}\text { P- } \\
\text { value }\end{array}$ \\
\hline Serum AST & $17(11-52)$ & $19(7-90)$ & 1589 & 0.33 \\
\hline Serum ALT & $10(3-79)$ & $10(2-41)$ & 1659 & 0.54 \\
\hline $\begin{array}{l}\text { Serum AST/ALT } \\
\text { ratio }\end{array}$ & $1.9(0.3-5)$ & $1.9(0.3-18)$ & 1758 & 0.93 \\
\hline
\end{tabular}

On plotting ROC curve for AST/ALT ratio values in determining the poor outcome i.e., occurrence of death in advanced stages of Cervical Cancer, Area under the curve (AUCs) was found to be not significant with very poor accuracy (AUC $=0.47, \mathrm{P}$ $=0.73$ ). Similarly, Area under the curve (AUCs) were found to be not significant for ALP values in determining death in advanced stages of Cervical Cancer with poor accuracy (AUC $=0.66, \mathrm{P}=0.05$ ). (Graphs 1 \& 2)

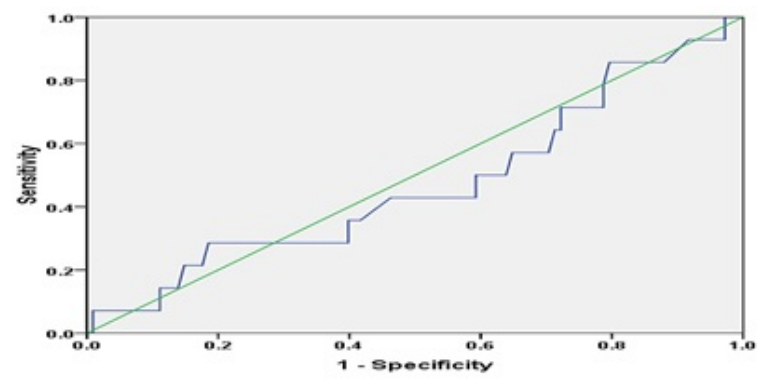

Graph-1: ROC curve for AST/ALT ratio values for occurrence of death in advanced stages of Cervical Cancer (AUC- 0.47, Significance 0.73)

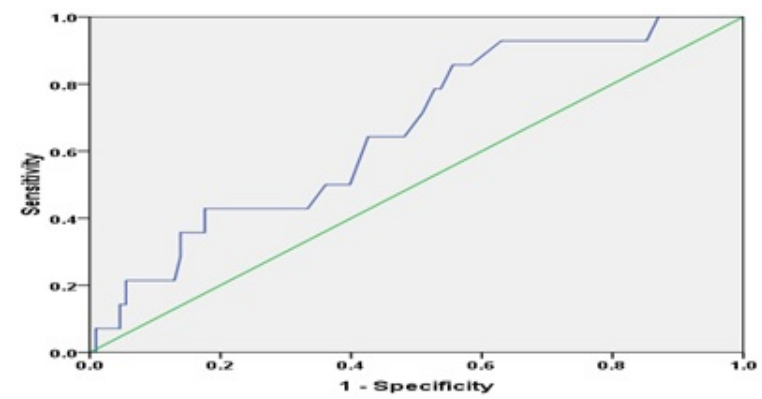

Graph-2: ROC curve for ALP values for occurrence of death in advanced stages of Cervical Cancer (AUC- 0.66, Significance 0.05)

Graph 3 \& 4 represents the Kaplan-Meier curve with one-year survival estimates for normal vs. abnormal alkaline phosphatase levels and normal vs. abnormal AST/ALT ratio respectively. It was observed that there was no statistically significant difference between the groups in their survival rates. $(P>0.05)$

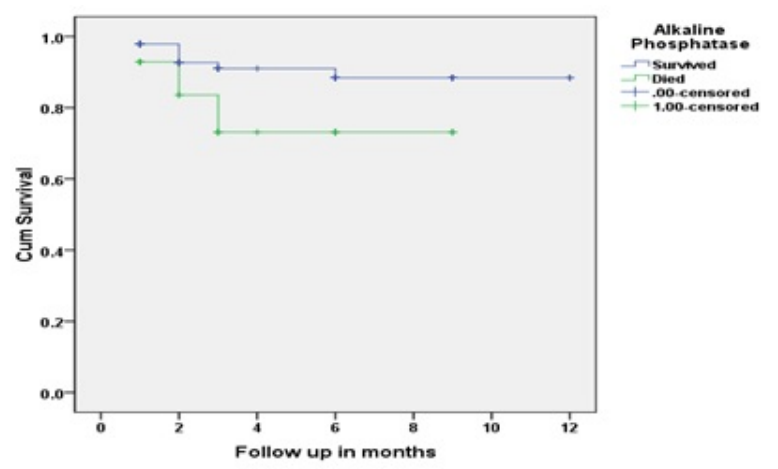

Graph-3: Kaplan-Meier survival curve among those with normal and abnormal alkaline phosphatase levels (Log rank value: 3.84 and Significance-0.05)

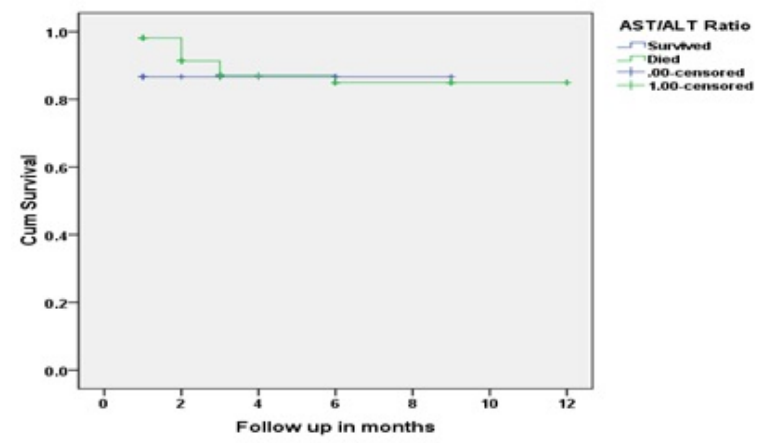

Graph-4: Kaplan-Meier survival curve among those with normal and abnormal AST/ALT ratio (Log rank value: 0.35 and Significance0.55)

The probability of survival was same among both the groups with normal (91.5\%; 95\% CI-83.4-95.9) and abnormal ALP levels (78.6\%; 95\% CI - 58.590.9) and similarly among normal (86.7\%; 95\% CI58.4-97.7) and abnormal AST/ALT ratio (88.8\%; 95\% CI - 80.1-93.8) ( $P>0.05)$. (Table4)

Table-4: Comparison of over-all survival among the groups with normal and abnormal 
ALP and AST/ALT levels.

\begin{tabular}{|l|l|l|l|l|}
\hline \multicolumn{2}{|c|}{ Particulars } & \multicolumn{1}{|c|}{$\begin{array}{c}\text { Events } \\
\text { (Deaths) }\end{array}$} & $\begin{array}{r}\text { Estimated 1-yr survival } \\
(\%, 95 \% \text { CI })\end{array}$ & $\begin{array}{c}\text { Log-rank P- } \\
\text { value }\end{array}$ \\
\hline \multirow{2}{*}{ ALP } & Normal & $8 / 94$ & $91.5 \%(83.4-95.9)$ & 0.05 \\
\cline { 2 - 4 } & Abnormal & $6 / 28$ & $78.6 \%(58.5-90.9)$ & \\
\hline \multirow{2}{*}{$\begin{array}{l}\text { AST/ALT } \\
\text { ratio }\end{array}$} & Normal & $2 / 15$ & $86.7 \%(58.4-97.7)$ & 0.55 \\
\cline { 2 - 4 } & Abnormal & $12 / 107$ & $88.8 \%(80.1-93.8)$ & \\
\hline
\end{tabular}

\section{Discussion}

The liver parameters such as alanine aminotransferase (ALT), aspartate aminotransferase (AST), AST/ALT ratio have prognostic significance in various clinical conditions of also non-liver origin based on the available literature. It could therefore be assumed that liver biomarkers could be associated with prognosis in malignant disease, even without direct hepatic involvement [3]. Hence in the present study, we assessed if the AST/ALT ratio could predict the prognosis of advanced cancer cervix before the initiation of treatment.

In the current study the mean age of the study participants was $50.4 \pm 10.64$ years and highest proportion of patients were in III B stage (57.4\%) whereas Pavo $\mathrm{N}$ et al., noted median age as 62 years and majority (33.0\%) of patients had stage IV cancer. The difference noted is due to different study design where Pavo $\mathrm{N}$ etal., considered patients with all type of cancers [3].

The mean serum AST, serum ALT were 21.21 10.39 $\mathrm{U} / \mathrm{L}, \quad 12.48 \pm 10.86 \mathrm{U} / \mathrm{L}$ respectively which is comparable to the findings of Pavo $\mathrm{N}$ et al., where mean serum ALT and AST were 22 (16-32) U/L and 24 (19-31) U/L respectively [3]. Veeramalla $V$ noted the mean value of serum AST and ALT to be $50.60 \pm 16.61 \mathrm{U} / \mathrm{L}$ and $50.28 \pm 15.25 \mathrm{U} / \mathrm{L}$ were higher than our findings. He also compared the values with controls and found that the mean serum AST, ALT values were significantly higher in cervical cancer cases compared to controls $(30.43 \pm 3.22 \mathrm{U} / \mathrm{L}$ and $34.47 \pm 4.32 \mathrm{U} / \mathrm{L}$ respectively) [8].

The difference may be due to different cancer stages of the patients included in the study. Mean serum AST/ALT ratio was $2.3 \pm 1.9$, however, according to study by Thriveni Ket al., the mean AST/ALT ratio based on different stages of breast cancer were stage I $(1.18 \pm 0.15)$, stage II $(1.34 \pm 0.22)$, stage III $(1.61 \pm 0.30)$ and stage IV $(1.72 \pm 0.38)$ [9]. and as there were no data on AST/ALT ratio in cervical cancer, the levels have been compared to breast cancer.
In this study, mean total bilirubin and serum albumin, were $0.43 \pm 0.22 \mathrm{mg} / \mathrm{dl}$ and $3.92 \pm 0.45 \mathrm{~g} / \mathrm{dl}$ respectively whereas according to Pavo $\mathrm{N}$ et al., mean total bilirubin and serum albumin were 0.58 $\mathrm{mg} / \mathrm{dl}$ and $4.3 \mathrm{~g} / \mathrm{dl}$, respectively which are in line with our findings. 3In a study by Li Jet al., the median fasting blood glucose was $91.1 \mathrm{mg} / \mathrm{dl}$ (range: 71.4-98.2) and $110.7 \mathrm{mg} / \mathrm{dl}$ (range: $100.0-$ 180.4) in the euglycemic and hyperglycemic groups, respectively whereas in our study we noted the mean random blood glucose level to be $130.4 \pm 63.87 \mathrm{mg} / \mathrm{dl}$ with a range of $67-510 \mathrm{mg} / \mathrm{dl}$ [10]. Mean total proteins was $7.79 \pm 0.57 \mathrm{~g} / \mathrm{dl}$ which is comparable to the findings noted by Nyarota Ket al in Zimbabwe (7.29 $\pm 0.57 \mathrm{~g} / \mathrm{dl})$ [11]. According to Devi LI et al, who has studied serum biochemical profile of patients suffering from cervical cancer in Mizoram has noted the random blood glucose level of $99.63 \pm 49.57 \mathrm{mg} / \mathrm{dl}$ ranging from 52 to 212 $\mathrm{mg} / \mathrm{dl}$.

The plasma total protein and albumin, levels were $7.38 \pm 0.79 \mathrm{~g} / \mathrm{dl}$ and $4.13 \pm 0.61 \mathrm{~g} / \mathrm{dl}$ respectively. The total and direct bilirubin levels observed were of $0.36 \pm 0.10 \mathrm{mg} / \mathrm{dl}$ and $0.19 \pm 0.12 \mathrm{mg} / \mathrm{dl}$ respectively. 12Mean serum Alkaline Phosphatase noted in this study was $101.05 \pm 38.48 \mathrm{U} / \mathrm{L}$ which is comparable to findings of Devi LI et al., which was $110.13 \pm 64.63 \mathrm{U} / \mathrm{L}$ [12]. Mean follow up period was $4 \pm 3$ months with a range of $1-12$ months, at the end of follow up period $11.5 \%$ of the study participants had died whereas in a study by Huang $\mathrm{H}$ et al., the follow-up period ranged from 1 month to 5 years and they also noted that 248 (55.5\%) cancer-related deaths at the last clinical follow-up session [13]. The lower mortality observed in our study may be due to short follow up period.

In the current study we observed that the difference among median serum AST, ALT and de-ritis ratio with different stages was not found to be statistically significant ( $P>0.05)$ with slightly higher median serum AST levels being noted among advanced stage ( $\geq$ III B Stage) but according to Thriveni Ket al, significant elevation of AST/ALT ratio was noted in advanced stages of the disease and also in larger tumor size which could probably be due to the degree of necrosis of the tumor and the lack of significance in our study might be due to smaller sample size in our study. 9 Similarly Manju $\mathrm{V}$ et al., have concluded that higher levels of AST, ALT and $A L P$, in the circulation of cervical cancer patients may be used in the diagnosis and treatment monitoring of patients with cervical carcinoma [7]. 
Our study being the first one to look at the role of pre-treatment de-ritis ratio as a marker for cervical cancer, serum AST/ALT ratio and ALP values were noted to have a very poor accuracy ( $A \cup C=0.47, P$ $=0.73$ ) and ( $A U C=0.66, P=0.05)$ respectively in determining the fatal outcome (death in advanced stages of Cervical Cancer) whereas Veeramalla $\mathrm{V}$ has concluded that mean values of serum AST and ALT can be used as tumor markers in the management of malignancy of the uterine cervix as the meanswere higher in cervical cancer cases compared to controls [8].

In this pioneer study, we also assessed the probability of survivalamongthe groups with normal (86.7\%; 95\% CI-58.4-97.7) and abnormal AST/ALT ratio (88.8\%; 95\% CI - 80.1-93.8). It was observed that there was no statistically significant difference between the groups in their survival rates $(P>0.05)$. But Huang Het al., in his study concluded that increased levels of AST/ALT ratio might predict shorter overall survival in esophageal squamous cell carcinoma (ESCC) patients suggesting that serum AST/ALT ratio could be used as a key predictor of survival in patients with ESCC [13]. The difference in the observations may be due to shorter follow up period of one year in this study.

\section{Limitations}

The study is retrospective in nature and has a small sample size. Further studies with higher sample sizes and prospective designs addressing the confounders are recommended to establish the association. Survival rates were studied using oneyear survival estimates and it would be ideal to assess 5-year survival to generalize the results and also to get better survival estimates.

\section{Conclusion}

- AST/ALT ratio had a very poor accuracy in determining the poor outcome i.e., occurrence of death in advanced stages of Cervical Cancer.

- Hence AST/ALT ratio cannot predict the prognosis of advanced cancer cervix before the initiation of treatment.

\section{What this study adds to the existing knowledge?}

This study is an exploratory study which is a first of its kind conducted to elicit the role of pre-treatment deritis-ratio as a prognostic marker in cancer cervix.
Transaminases play a role in maintaining a normal and well-coordinated liver function. AST/ALT ratio has been linked as one of the markers during tissue injury. Due to excessive reactive oxygen species (ROS) during cancer progression, mitochondrial DNA damages resulting in severe tissue damage. Thus there is excess of mitochondrial enzyme being released i.e., AST, both cytosolic and mitochondrial enzyme. Significant elevation of AST/ALT ratio in advanced stages of the disease could be probably explained as being associated with the degree of necrosis of the tumor [8]. Thus by conducting this study we could rule out the use of pre-treatment serum AST/ALT ratio as a prognostic marker in cervical cancer.

\section{Contributions of the authors}

Sandeep Kumar: Formulated the idea for the study, data collection, manuscript writing, statistical analysis and editing Manisha Roy: Data collection Nupur Nelson: Data Collection, Govardhan: Data collection, Statistical analysis Khaleel:Data Collection, manuscript editing Pallavi R: Manuscript writing and editing, Ramesh G: Manuscript editing.

\section{Reference}

01. Kumar R. Prevalence of female reproductive tract cancer in a teaching hospital of Rohtas District, Bihar, India. Int J Res Med Sci. 2018;6(12)4058-62.

doi.org/10.18203/2320-6012.ijrms20184907

[Crossref]

02. Srivastava S, Natu SM, Gupta A, et al. Lipid peroxidation and antioxidants in different stages of cervical cancer- Prognostic significance. Indian J Cancer. 2009 Oct-Dec;46(4)297-302. doi: 10.4103/0019-509X.55549 [Crossref]

03. Antébi $H$, Mansoor $O$, Ferrier $C$, et al. Liver function and plasma antioxidant status in intensive care unit patients requiring total parenteral nutrition- comparison of 2 fat emulsions. JPEN J Parenter Enteral Nutr. 2004 May-Jun;28(3)142-8.

DOI: $10.1177 / 0148607104028003142$ [Crossref]

04. Botros $M$, Sikaris KA. The de ritis ratio- the test of time. Clin Biochem Rev. 2013 Nov;34(3)11730.

[Crossref] 
05. Rief $P$, Pichler $M$, Raggam $R$, et al. The AST/ALT (De-Ritis) ratio- A novel marker for critical limb ischemia in peripheral arterial occlusive disease patients. Medicine (Baltimore). 2016 Jun;95(24)e3843.

doi: 10.1097/MD.0000000000003843 [Crossref]

06. Chougule A, Hussain S, Agarwal DP. Prognostic and diagnostic value of serum pseudocholinesterase, serum aspartate transaminase, and serum alinine transaminase in malignancies treated by radiotherapy. J Cancer Res Ther. 2008 Jan-Mar;4(1)21-5. [Crossref]

07. Manju V, Balasubramanian V, Nalini N. Oxidative stress and tumor markers in cervical cancer patients. J Biochem Mol Biol Biophys. 2002 Dec;6(6)387-90.

DOI: $10.1080 / 1025814021000036115$ [Crossref]

08. Veeramalla V. Pseudocholinesterase, aspartate transaminase, alanine transaminase as markers for cervical cancer- a study in a tertiary care hospital. Int J Adv Med. 2017;4(6)1557-61.

doi: 10.18203/2349-3933.ijam20175134 [Crossref]

09. Thriveni K, James $R$, Krishnamoorthy $L$, Deshmane V. Serum Transaminases Ratio in Breast Cancer Patients. Austral - Asian J Cancer. 2009;8(4)199-201.

[Crossref]
10. Li J, Wu MF, Lu HW, Zhang BZ, Wang LJ, Lin ZQ. Impact of hyperglycemia on outcomes among patients receiving neoadjuvant chemotherapy for bulky early stage cervical cancer. PloS one. 2016;11(11).

doi: 10.1371/journal.pone.0166612 [Crossref]

11. Nyarota K, Zhou DT. Albumin and Total Protein in Cancer Patients at Radiotherapy Clinic, Zimbabwe. Saudi J Med Pharm Sci. 2017;3(10A)1071-1076.

Available at: [Article] [Crossref]

12. Devi LI, Ralte L, Hmar L, Ali MA. Serum biochemical profile of patients suffering from cervical cancer in Mizoram. International Journal of Chemical Studies. 2018;6(6)883-886.

[Crossref]

13. Huang $H$, Wang $X P$, Li XH, et al. Prognostic value of pre-treatment serum alanine aminotransferase/ aspartate aminotransferase (ALT/AST) ratio and gamma glutamyl transferase (GGT) in patients with esophageal squamous cell carcinoma. BMC Cancer. 2017Aug14;17(1)544.

doi: 10.1186/s12885-017-3523-y [Crossref] 